J. Amer. Soc. Hort. Sci. 116(3):405-411. 1991.

\title{
Development of a Seedling-applied Antitranspirant Formulation to Enhance Water Status, Growth, and Yield of Transplanted Bell Pepper
}

\author{
Peter Nitzsche', Gerald A. Berkowitz'and Jack Rabin ${ }^{3}$ \\ Rutgers-The State University of New Jersey, New Brunswick, NJ 08903 \\ Additional index words. Capsicum annuum, paraffin wax emulsion, water stress, transplant shock, surfactant
}

\begin{abstract}
"Abstract. The objective of this research was to develop an effective antitranspirant formulation for reducing transplant shock (transitory water stress) in bell pepper (Capsicm annuum L.) seedlings. A formulation with a paraffin wax emulsion (Folicote at $5 \%$ ) and a spreader/sticker type surfactant (Biofilm at $0.5 \%$ ) was effective as an antitranspirant. This formulation was less phytotoxic than other formulations tested. Application of the formulation led to increased leaf water potential $(\Psi \mathrm{w}$ ) $\mathrm{i}$ in transplanted seedlings for several days as compared with untreated transplants. When this, (relatively) nonphytotoxic formulation was used in a field study for 1 year, increased seedling $\Psi$ w during a period of imposed water stress led to less leaf abscission and increased plant growth throughout the growing season. Chemical names used: alkylarylpolyethoxyethanol (Biofilm).
\end{abstract}

References regarding the use of antitranspirants to ameliorate the detrimental effects of water deficits on crop growth date back to Theophrastus in 300 B.C. (Gale and Hagan, 1966). Commercial usefulness of antitranspirants has been limited, however, by the typical reduction in $\mathrm{CO}_{2}$ uptake (inhibiting photosynthesis) that occurs concomitantly with reduced transpirational water loss when $r_{L}$ is increased. Even though the transpiration ratio (grams of $\mathrm{C}_{2}$ fixed per grams of $\mathrm{H}_{2} \mathrm{O}$ lost) is often increased by an antitranspirant (e.g., Davies and KozIowski, 1974), a review of the pertinent literature (Jones, 1981) has pointed out that the practical net effect of antitranspirant application under most agronomic conditions is invariably a reduction in yield.

However, use of an antitranspirant to alleviate plant water stress under some specific conditions may have an overall positive effect on potential crop quality, maturity date, or yield. One example is the water deficits that develop in vegetable crop seedlings immediately after transplanting into the field. Restricted water uptake from damaged roots of transplanted seedlings can lead to sudden and severe plant water deficits ("transplant shock"). In a previous study, Berkowitz and Rabin (1988) characterized transplant shock in pepper seedlings as a decline in $\Psi_{\mathrm{w}}$ (by as little as $0.6 \mathrm{MPa}$ ) within hours after transplanting and for as short as $24 \mathrm{~h}$. In that study, when transplants were irrigated within a day after setting out, the transitory stress led to yield reductions. Working with an abscisic acid seedling dip, Berkowitz and Rabin (1988) have shown that brief antitranspirant-induced increases in leaf resistance and $\Psi \mathrm{w}$ immediately after transplanting led to significant increases in plant water status of bell pepper seedlings and subsequent yield of fruit.

We now report on the development and evaluation of an an-

Received for publication 15 June 1989. New Jersey Agr. Expt. Sta. Publication no. 12149-5-89. supported bv Hatch Act and state funds. Mention of trade names or vendors does not imply endorsement by Rutgers Univ. or Rutgers Cooperative Extension of the products named nor criticism of similar ones not mentioned. The cost of publishing this paper was defrayed in part by the payment of page charges. Under postal regulations, this paper therefore must be hereby marked advertisement solely to indicate this fact.

'Horticulture and Crops Dept., Cook College.

${ }^{2}$ Horticulture and Crops Dept., Cook College. Author to whom reprint requests should be addressed.

${ }^{3}$ Rutgers Cooperative Extension of Cumberland County, R.D. 1, Box 319B, Morton Ave., Millville, NJ 08332-9776. titranspirant formulation for use as a foliar drench on bell pepper seedlings that are subsequently transplanted into the field. Studies were undertaken with a commercially available wax emulsion (Folicote, Aquatrols Corp. Pennsauken, N. J.) and a range of surfactants (i.e., nonionic, spreader/sticker, ionic, crop oil, and other surfactant types) in order to develop a formulation with potential commercial usefulness.

\section{Materials and Methods}

Initially, we screened a wax emulsion (Folicote) alone and in combination with several surfactants using leaf water loss and $r_{L}$ studies to determine the effectiveness of various formulations. The formulation $15 \%$ Folicote plus $0.5 \%$ X-77 was then chosen from these studies for use in field research in 1987. Since the antitranspirant proved to be phytotoxic, further leaf water loss, $\mathrm{r}_{\mathrm{L}}$, ethylene, and growth studies were performed in the greenhouse to determine the phytotoxic agent in the formulation and to develop a nonphytotoxic one. This new formulation (5\% Folicote and $0.5 \%$ Biofilm) was then evaluated in field studies in 1988.

Plant material. Bell pepper (CV. Lady Bell) seedlings were grown for 10 to 12 weeks in $53 \times 27 \times 5.5-\mathrm{cm}$ flats $(250$ per flat for field studies, or 80 per flat for all other experiments) with 1 peat : 1 vermiculite mix (v/v) under ambient conditions in a glass greenhouse. After emergence, flats were irrigated weekly with $0.6 \mathrm{~g}(15 \mathrm{~N}-6.5 \mathrm{P}-12.4 \mathrm{~K})$ fertilizer/liter. Plants also were watered to runoff as needed and $1 \mathrm{~h}$ before any study was initiated. For all studies using individual leaves, the youngest, fully expanded leaf of a seedling was used.

Water relations. $\mathrm{r}_{\mathrm{L}}$ was calculated as the product, divided by the sum, of abaxial and adaxial stomatal resistance measurements. Stomatal resistance measurements were recorded with a LI-COR Model 1600 diffusive resistance porometer (LI-COR, Lincoln, Neb.). $\Psi$ w was measured with a pressure chamber (Soil Moisture Equipment Corp., Santa Barbara, Calif.). Both $\Psi \mathrm{W}$ and $\mathrm{r}_{\mathrm{L}}$ were measured in the field at midday (12:00 to 2:00 PM) unless otherwise noted.

Plant growth Measurements of total leaf area were made nondestructively with a LI-COR Model 3000 portable leaf area

Abbreviations: $\Psi_{\mathrm{W}}$, leaf water potential; $\mathrm{r}_{\mathrm{L}}$, leaf resistance; SLW, specific leaf weight. 
meter. For SLW studies, a LI-COR Model 3100 leaf area meter was used to measure the area of excised leaves.

Antitranspirant formulation effectiveness. Antitranspirant treatments (5\% Folicote with the surfactants X-77, Biofilm, Li700, Aquagro, and Tween-20 at $0 \%$ to $0.5 \%$ ) were applied $1 \mathrm{~h}$ before leaf excision. After leaves were excised and weighed, petioles were sealed with Parafilm and leaves were placed in a growth chamber at $29 \mathrm{C}, 38 \% \mathrm{RH}$, and $175 \mu, \mathrm{mol} \cdot \mathrm{s}^{-1} \cdot \mathrm{m}^{-2}$ photosynthetically active radiation. Weight loss was ascertained after precisely $30 \mathrm{~min}$. Nine replicates (individual leaves) were used per treatment. Control leaves were dipped in water. This in vitro leaf-dehydration assay of formulation effectiveness was followed by measuring $\mathrm{r}_{\mathrm{L}}$ of intact leaves. Antitranspirant treatments ( $5 \%$ to $35 \%$ Folicote with $\mathrm{X}-77$ at $0.1 \%$ to $1.5 \%$ ) were applied by dipping well-watered seedlings (five leaves on separate seedlings per treatment) in the formulations $1 \mathrm{~h}$ before measurement of $r_{L}$. Control leaves were dipped in water.

Growth and water relations (/ield). Plots (four replications per treatment) were set up in a completely randomized design at two field sites (Bridgeton and New Brunswick, N. J.) in 1987, and one field site (Bridgeton) in 1988. Each plot contained six rows (1.2 m between rows) with 12 plants per row $(0.3 \mathrm{~m}$ between each plant in a row). The soil at Bridgeton was a Sassafras sandy loam (fine-loamy, siliceous, mesic, Typic Hapludults). The soil at New Brunswick was a Colt's Neck loam (fine-loamy, mixed, mesic, Typic Hapludults). In 1987, 56N-

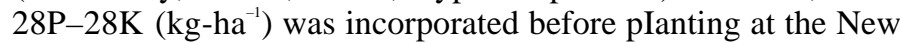
Brunswick site. This site also received two sidedressings of $36 \mathrm{~N}-18 \mathrm{P}-18 \mathrm{~K}$ (kg" ha-1) at 24 and 46 days after transplanting. The Bridgeton plots received $46 \mathrm{~N}-23 \mathrm{P}-23 \mathrm{~K}\left(\mathrm{~kg} \cdot \mathrm{ha}^{-1}\right)$ before planting and one sidedressing of $46 \mathrm{~N}-23 \mathrm{P}-23 \mathrm{~K}$ (kg-ha-l) in 1987 and 1988. For all field experiments, no supplemental irrigation was supplied to the plots before setting out transplants. In 1987, the Bridgeton field received $19 \mathrm{~mm}$ and the New Brunswick field $71 \mathrm{~mm}$ of rain during the 2 weeks before transplanting. The soil gravimetric water content $(15-\mathrm{cm}$ depth) at the time of transplanting was 0.065 and $0.086 \mathrm{~g}$ water/g dry soil, respectively. In 1988, the Bridgeton site received $26 \mathrm{~mm}$ of rain during the 2 weeks before transplanting. The gravimetric water content at the time of transplanting was $0.033 \mathrm{~g}$ water/g dry soil.

The foliage of the seedlings was dipped in the antitranspirant formulations after seedlings were removed bareroot from their starting flats and before transplanting. The 1987 formulation consisted of $15 \%$ Folicote and $0.5 \% \mathrm{X}-77$ in water and the 1988 formulation was 5\% Folicote and $0.5 \%$ Biofilm in water. The control seedlings had their foliage dipped in water in both years. The 1988 study had an additional control treatment in which seedlings were not transplanted and were grown in $2000-\mathrm{cm}^{3}$ plastic pots placed alongside the other rows in the field. The pots were filled with 1 peat : 1 vermiculite mix (v/v) and kept well-watered throughout the experiment. After transplanting, initial irrigations were supplied from a trickle system. In 1987, both sites were irrigated on the 3rd day after transplanting. In 1988, the Bridgeton site was irrigated on the 6th day after transplanting. Other than initiaI irrigations, all cultural management practices were designed to optimize plant growth and fruit yield.

Leaf abscission measured at New Brunswick in 1987 and at Bridgeton in 1988 was calculated as the percentage of leaves remaining on a plant on day 14 after transplanting as compared with the number of leaves present on the plant on day 0. SLW was measured 10 days after transplanting on 20 detached leaves per treatment. Yield in 1988 was measured by harvesting all the marketable fruit ( $>50 \mathrm{~g}$ ) three times at weekly intervals. The first (early) harvest was 73 days after transplanting. The fruit were harvested from the middle four rows of each plot.

In 1987, a second field experiment was set out at the New Brunswick site next to the main field site. For this experiment, all growing conditions (cultural management, plot size, etc.) were similar to the main New Brunswick experiment of 1987, except that no fertilizer sidedressings were applied and seedlings were transplanted into these plots on 17 Aug. For this experiment, foliar dip antitranspirant formulations of 5\%,10\%, and $15 \%$ Folicote (all with $0.5 \% \mathrm{X}-77$ ) were compared with a control where plants were dipped in water before transplanting. For this experiment, $\Psi \mathrm{W}$ after transplanting and leaf abscission were the only criteria evaluated.

Antitranspirant formulation phytotoxicity. Antitranspirant formulation components (Folicote and the surfactants X-77 and Biofilm) were evaluated for phytotoxicity by monitoring their effects on the extent of ethylene evolution from detached, waterstressed pepper leaves, and by monitoring their effects on the growth and/or abscission of intact leaves after application to pepper seedlings. For the ethylene studies, leaves (four per treatment) of well-watered seedlings were dipped in antitranspirant solutions (water control, 5\% Folicote, 0.5\% X-77, 5\% Folicote $+0.5 \%$ X-77, $0.5 \%$ Biofilm, and 5\% Folicote $+0.5 \%$ Biofilm) without detaching them from the plants, and then allowed to dry for $1 \mathrm{~h}$. Leaves were then excised and subjected to an in vitro water stress treatment by allowing them to dehydrate at $27 \mathrm{C}, 25 \% \mathrm{RH}$, and $160 \mu \mathrm{mol} \cdot \mathrm{s}^{-1} \cdot \mathrm{m}^{-2}$ light until they lost $25 \%$ of their fresh weight. Leaves were then sealed in 60-mI glass test tubes (one leaf with $\approx 25 \mathrm{~cm}^{2}$ area per tube). Moistened filter paper was placed in the tubes with the leaves to avoid further desiccation of the detached leaves. Tubes were flushed with $\mathrm{N}_{2}$ after 30 min and then incubated for $24 \mathrm{~h}$ at $20 \pm 0.5 \mathrm{C}$. Ethylene production was measured by withdrawing a 1-ml gas sample from the headspace of each tube and injecting it into a flame ionization gas chromatography (GC-8AIF, Shimadzu Corp. Kyoto, Japan) containing a Porepak Q column, with the detector/injector at $170 \mathrm{C}$ and the column at $80 \mathrm{C}$.

To evaluate formulation phytotoxicity on intact plants, pepper seedlings (five per treatment) were removed from starting flats, their foliar portion dipped in the antitranspirant formulations (water control, 5\% Folicote, $0.5 \% \mathrm{X}-77,5 \%$ Folicote $+0.5 \%$ $\mathrm{X}-77,0.5 \%$ Biofilm, and $5 \%$ Folicote $+0.5 \%$ Biofilm) and transplanted into individual pots $\left(2 \mathrm{dm}^{3}\right)$ containing potting mix Water was withheld until $\Psi$ w reached about $-1.7 \mathrm{MPa}$ (i.e., 8 days after transplanting). Pots were then irrigated. Leaf abscission in this experiment was calculated as the percentage of leaves remaining on the plants on day 13 (after transplanting) as compared with the number of leaves on a plant on day $\mathrm{O}$ (day of transplanting).

Statistical analyses. All data were subjected to analysis of variance. Experiments that involved qualitative treatment levels were subsequently analyzed by a $t$ test (for comparison of two treatments) or Duncan's multiple comparison test (when more than two means were evaluated). Results of experiments that invoIved quantitative treatment levels (i.e., when several concentrations of Folicote and/or a surfactant comprised the treatments) were partitioned into linear and quadratic responses by regression analysis. Single-degree-of-freedom contrasts were also used to separate means in these studies. For experiments where no significant difference was found between treatment means, the standard error of the means is provided. 


\section{Results and Discussion}

Antitranspirant formulation effectiveness. Application of 5\% Folicote as a foliar dip did not significantly reduce the weight loss from detached pepper leaves (Table 1). In contrast, others (Davies and Kozlowski, 1974; Lipe and Skinner, 1979; Lipe et al., 1982) have indicated that the wax emulsion formulation used in our study (Folicote) is an effective antitranspirant when applied as a foliar spray. This in vitro screening assay did suggest, however, that the addition of certain surfactants to the formulation resulted in an antitranspirant effect. When the surfactants .Biofilm and the nonionic surfactant X-77 (alkylarylpolyoxethylene gIycol/free fatty acids/isopropanol) were added 'to the Folicote, water loss from the blades of detached pepper leaves was reduced (Table 1). The three formulations containing X-77 significantly reduced water loss relative to $5 \%$ Folicote alone. Water loss was also reduced as the concentration of Biofilm in the formulation increased. Li700 (phosphatidylcholine and methylacetic acid mixture) and two other surfactants, Aquagro (polyoxethylene esters of cyclic acids and polyoxethylene ethers of akylated phenols) and Tween-20 (polyoxethylene sorbitan monolaurate), did not enhance the antitranspirant effectiveness of Folicote (data not shown).

In greenhouse studies using intact plants, formulations with a range of Folicote or X-77 concentrations increased $r_{1}$ (Table 2). Formulations that contained $0.5 \% \mathrm{X}-77$ were effective as antitranspirants regardless of Folicote concentration (5\% to 35\%). In other experiments, formulations with Folicote alone (i.e., without a surfactant) never increased $r_{\llcorner}$over control values (data not shown). The studies on leaf water loss (Table 1) and $r_{t}$ (Table 2) led us to use 15\% Folicote and 0.5\% X-77 antitranspirant formulation for the field studies of 1987.

Growth and water relations, field (1987). Upon transplanting at the Bridgeton field site, $r_{\mathrm{L}}$ of pepper seedlings increased in a fashion typical of transplant shock (Fig. 1). The antitranspirant treatment resulted in increased $\mathrm{r}^{\mathrm{L}}$ as compared with $\mathrm{r}_{\mathrm{L}}$ in control seedlings on the day of transplanting and 1 day thereafter, although these differences were significant only on the day after transplanting (Fig. 1). Similar effects were observed at the New Brunswick field site; there was no consistent, significant effect

Table 1. Effect of surfactant type and concentration in an antitranspirant formulation with 5\% Folicote on the loss of water from excised pepper leaves (fresh-weight basis).

\begin{tabular}{lccc}
\hline \hline & \multicolumn{2}{c}{ Surfactant } \\
\cline { 2 - 4 } Concn (\%) & \multicolumn{3}{c}{ Type } \\
\cline { 2 - 4 } Biofilm & X-77 & Li-700 \\
\hline Water control & 14.0 & Water loss (\%) \\
0.0 & 12.8 & 14.0 & 14.0 \\
0.1 & 12.4 & 12.8 & 12.8 \\
0.3 & 9.9 & 10.4 & 12.4 \\
0.5 & 10.4 & 10.7 & 12.2 \\
Contrasts & & 10.0 & 11.6 \\
C vs. FL & NS & & \\
C vs. FL + FLS & $*$ & $* *$ & NS \\
FL vs. FLS & NS & $*$ & NS \\
Trends & & & NS \\
Linear & $*$ & NS & NS \\
Quadratic & NS & $*$ & NS \\
\hline
\end{tabular}

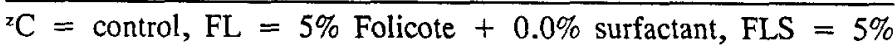

Folicote $+0.1 \%$ surfactant, $5 \%$ Folicote $+0.3 \%$ surfactant, and $5 \%$ Folicote $+0.5 \%$ surfactant.

Ns,*,**Nonsignificant or significant at $P=0.05$ or 0.01 , respectively. of the antitranspirant formulation on $\mathrm{r}_{\mathrm{L}}$ of transplanted seedlings (data not shown). Possibly, transplant shock-induced $r_{L}$ increases in control seedlings (Fig. 1) could explain why no clear difference was evident between $r_{L}$ of control and treated seedlings. Antitranspirant formulation effects were demonstrated more

Table 2. Effect of varying wax emulsion (5\% Folicote) and surfactant (X-77) concentrations on leaf resistance of well-watered pepper seedlings as measured in the greenhouse. Controls were dipped in water. In expt. 1, all treatments, except water control, contained $5 \%$ Folicote; in expt. 2, all treatments except water control contained $0.5 \% \quad x-77$.

\begin{tabular}{|c|c|}
\hline eatment & $\begin{array}{l}\text { Leaf resistance } \\
\left(\mathrm{s}^{\cdot} \mathrm{cm}^{-1}\right)\end{array}$ \\
\hline \multicolumn{2}{|l|}{ speriment $1(\% \mathrm{X}-77)$} \\
\hline Water control & 1.56 \\
\hline 0.1 & 1.54 \\
\hline 0.5 & 2.52 \\
\hline 1.0 & 2.13 \\
\hline 1.5 & 2.60 \\
\hline \multicolumn{2}{|l|}{ ontrast } \\
\hline $\begin{array}{l}\text { C vs. } X^{z} \\
\text { ends }\end{array}$ & $* *$ \\
\hline Linear & NS \\
\hline speriment 2 (\% Folicote) & NS \\
\hline Water control & 0.70 \\
\hline 15 & 1.05 \\
\hline 25 & 1.02 \\
\hline 35 & 1.29 \\
\hline \multicolumn{2}{|l|}{ ontrast } \\
\hline $\begin{array}{l}\mathrm{C} \text { vs. } \mathrm{F}^{y} \\
\text { ends }\end{array}$ & $* *$ \\
\hline Linear & NS \\
\hline Quadratic & NS \\
\hline
\end{tabular}

$=$ control, and $\mathrm{X}=5 \%$ Folicote $+0.5 \% \mathrm{X}-77,5 \%$ Folicote + $0 \% \mathrm{X}-77$, and $5 \%$ Folicote $+1.5 \% \mathrm{X}-77$

$:=$ control, and $\mathrm{F}=15 \%$ Folicote $+0.5 \% \mathrm{X}-77,25 \%$ Folicote $0.5 \% \mathrm{X}-77$, and $35 \%$ Folicote $+0.5 \% \mathrm{X}-77$.

.**Nonsignificant or significant at $P=0.01$, respectively.

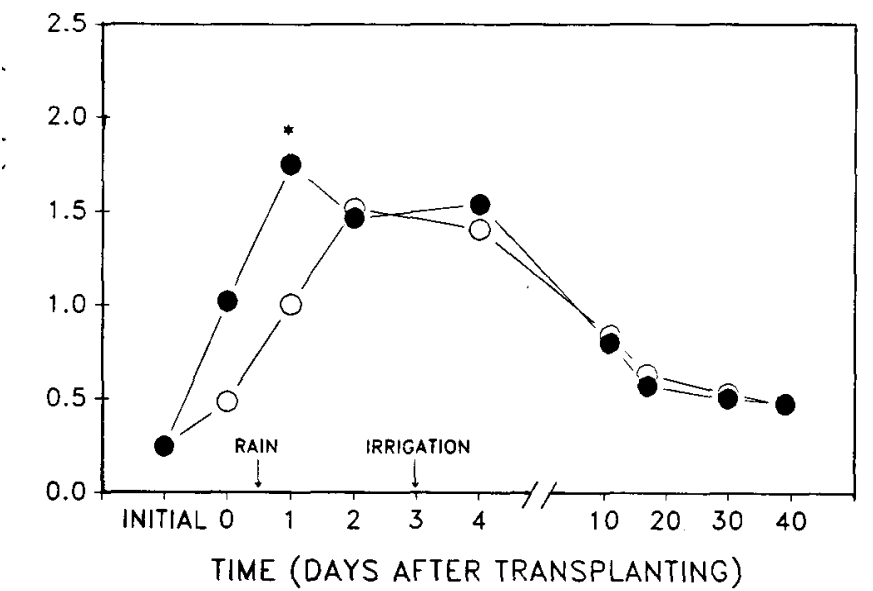

Fig. 1. $\mathrm{r}_{\mathrm{L}}$ for transplanted pepper seedlings treated with the antitranspirant formulation $15 \%$ Folicote and $0.5 \%$ X-77 ( - - ) or with water $(0-0)$; field experiment, Bridgeton, 1987. * Denotes a significant difference $(\boldsymbol{P}=0.05)$ on a given day between the two treatments. During the evening on the day of transplanting, $3 \mathrm{~mm}$ of rain fell on the plots. Initial $r_{L}$ was measured in the field on seedlings just before removal from flats. Readings of $r_{\mathrm{L}}$ presented as recorded "O" days after transplanting were made $1 \mathrm{~h}$ after transplanting. 


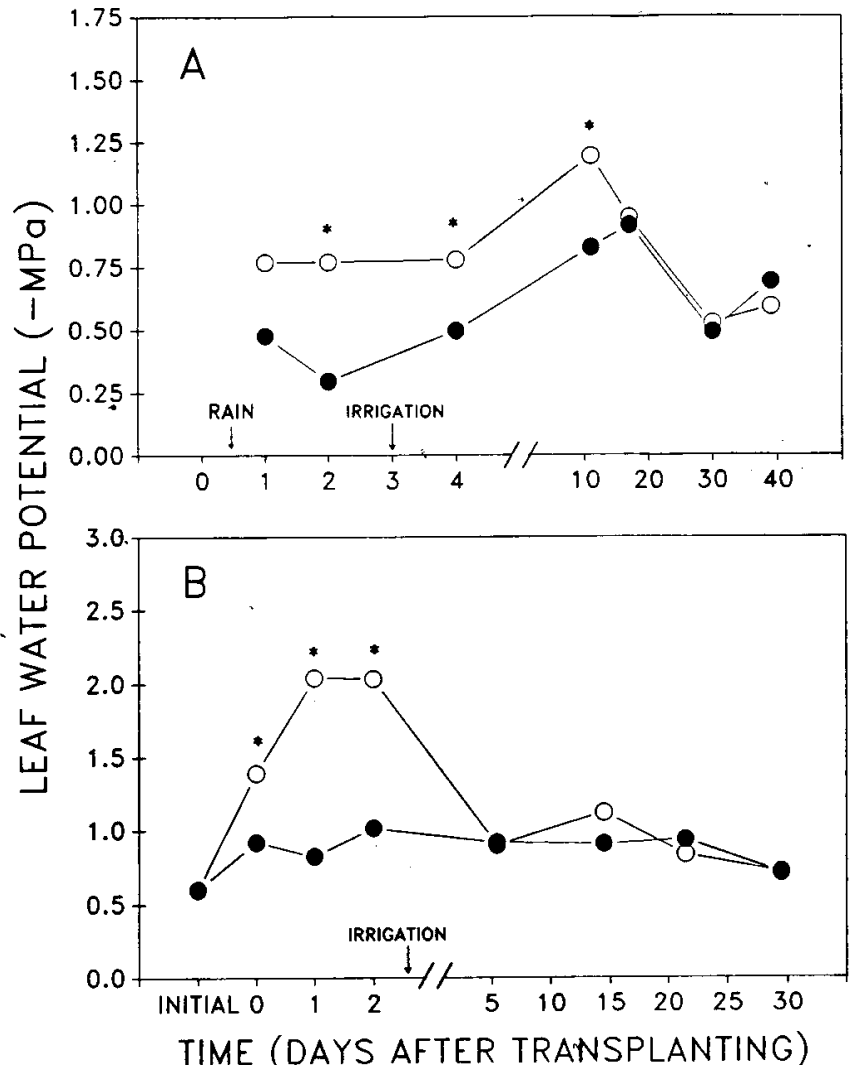

Fig. 2. $\Psi \mathrm{W}$ for transplanted pepper seedlings treated with the antitranspirant formulation $15 \%$ Folicote and $0.5 \%$ X-77 ( - - ) or with water $(\mathrm{O}-\mathrm{O})$; field experiments, Bridgeton (A) and New Brunswick (B), 1987. * Denotes a significant difference $(\boldsymbol{P}=0.05)$ on a given day between the two treatments. Initial $\Psi \mathrm{W}$ was measured in the field on seedlings just before removal from flats. Readings of $\Psi$ w presented as recorded " 0 " days after transplanting were made $1 \mathrm{~h}$ after transplanting seedlings. Initial and "day 0 " $\Psi \mathrm{w}$ were not recorded at Bridgeton in this experiment.

clearly by monitoring $\Psi \mathrm{w}$ in seedlings after transplanting at the two field sites (Fig. 2). Seedlings at the Bridgeton site treated with Folicote plus X-77 maintained substantially higher $\Psi \mathrm{w}$ than control seedlings for 11 days after transplanting (Fig. 2A). At the new Brunswick site, the antitranspirant increased $\Psi \mathrm{w}$ for 2 days after transplanting as compared with control seedlings (Fig. 2B). The enhancement of (post-transplant) leaf water status by treatment of seedlings with an antitranspirant before transplanting was substantial at both field sites. At Bridgeton, the maximum difference between $\Psi \mathrm{w}$ of control and Folicote-treated seedlings was $0.5 \mathrm{MPa}$ (day 2, Fig. 2A); at New Brunswick it was $1.2 \mathrm{MPa}$ (day 1, Fig. 2B).

Despite the enhancement of plant water status by application of the antitranspirant formulation, no beneficial effect of the treatment was found on plant growth. Leaf area of treated seedlings declined relative to the controls during the 2 nd and $3 \mathrm{rd}$ weeks after transplanting at New Brunswick (Table 3). Leaf count per seedling taken on the day of transplanting and 14 days thereafter indicated that the reduction of leaf area in treated as compared with control seedlings at New Brunswick was caused by a substantial increase in leaf abscission in plants treated with the antitranspirant formulation (Table 3). At Bridgeton, the antitranspirant formulation did not significantly affect seedling leaf area or abscission, although trends were similar to those for New Brunswick (data not shown).

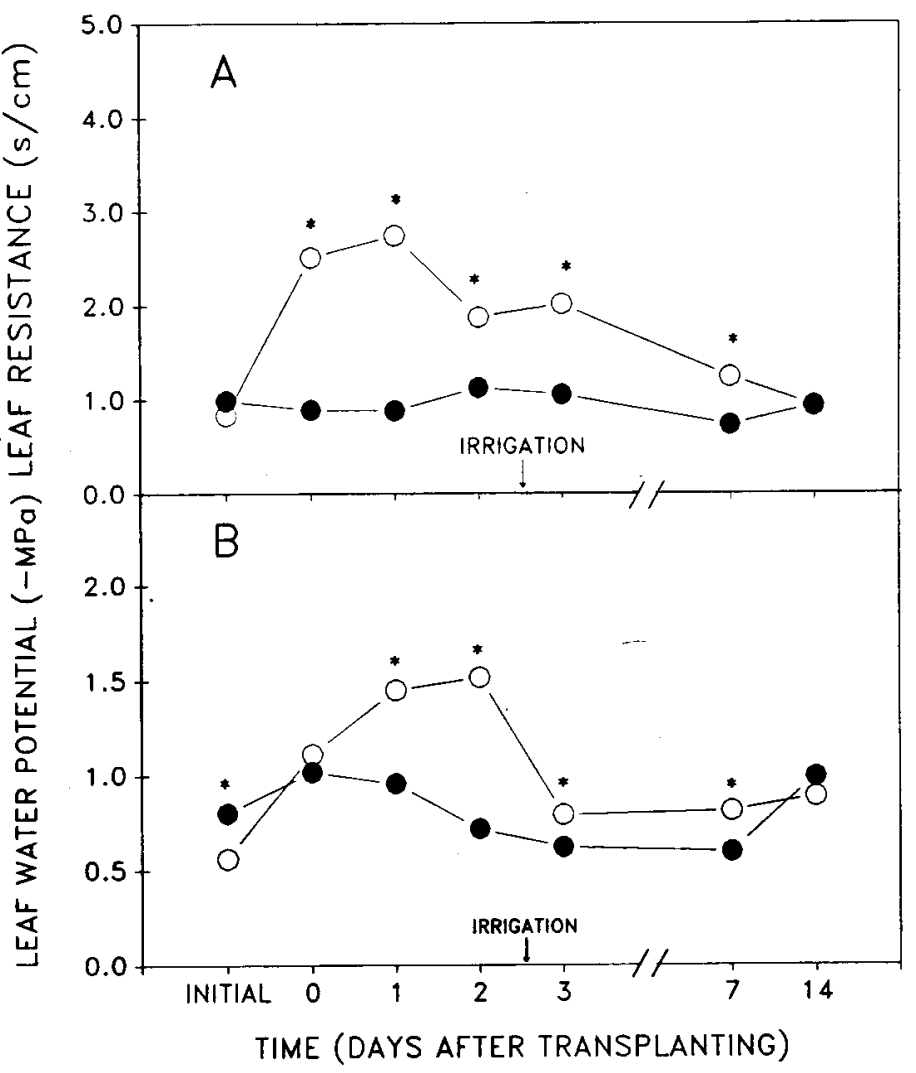

Fig. 3. $\mathrm{r}_{\mathrm{L}}(\mathrm{A})$ and $\Psi \mathrm{W}(\mathrm{B})$ measurements of pepper seedlings transplanted $(\mathrm{O}-\mathrm{O})$ or set out in pots and kept well-watered $(\mathbf{0}-\mathbf{0})$ (1988). All measurements were taken on seedlings not treated with any antitranspirant. * Denotes a significant difference $(\boldsymbol{P}=0.05)$ on a given day between transplanted and nontransplanted seedlings. Initial $\Psi \mathrm{W}$ was measured in the field on seedlings to be transplanted just before their removal from flats. Initial $\Psi \mathrm{w}$ of seedlings kept in the pots was measured at the same time. Readings of $\Psi \mathrm{w}$ presented as recorded $\mathrm{O}$ days after transplanting were made $1 \mathrm{~h}$ after transplanting of the seedlings.

Table 3. Effect of the antitranspirant formulation $15 \%$ Folicote plus $0.5 \%$ X-77 on leaf area per seedling and percent leaf abscission of transplanted seedlings in-the field (New Brunswick, 1987).

\begin{tabular}{|c|c|c|c|c|c|}
\hline \multirow{3}{*}{$\begin{array}{l}\text { Antitranspirant } \\
\text { applied }\end{array}$} & \multirow{2}{*}{\multicolumn{4}{|c|}{$\frac{\text { Leaf area/seedling }\left(\mathrm{cm}^{2}\right)^{z}}{\text { Days after transplanting }}$}} & \multirow{3}{*}{$\begin{array}{c}\text { Leaf } \\
\text { abscission } \\
(\%)\end{array}$} \\
\hline & & & & & \\
\hline & 1 & 8 & 14 & 20 & \\
\hline No & $51.5 \mathrm{a}$ & $47.3 \mathrm{a}$ & $51.8 \mathrm{a}$ & $61.1 \mathrm{a}$ & $12.8 \mathrm{a}$ \\
\hline Yes & $42.4 \mathrm{a}$ & $21.5 \mathrm{a}$ & $11.5 \mathrm{~b}$ & $12.0 \mathrm{~b}$ & $77.5 \mathrm{~b}$ \\
\hline
\end{tabular}

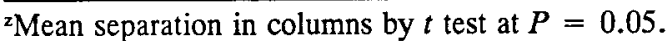

yMeasured on day 14 after transplanting.

The lack of normal plant growth (Table 3) suggested that the antitranspirant formulation may have been phytotoxic. Increased $r_{L}$ in plants subjected to high radiant heat flux (i.e., field conditions) may be injurious due to increased leaf temperature (Jones, 1986). However, measurements made with an infrared thermometer on a clear day indicated that the antitranspirant treatment did not cause a measurable increase in leaf temperature (data not shown). We observed that, after relief of stress, new leaves developing on antitranspirant-treated seedlings appeared wrinkled. This phytotoxic effect of the formulation was reflected in changes in SLW. The leaf wrinkling induced by the antitranspirant presumably caused less leaf area to be projected 
on a flat surface per unit of leaf weight. The mean SLW of control seedlings was $46.1 \mathrm{~cm}^{2} \cdot \mathrm{g}^{-1}( \pm 2.1 \mathrm{SE})$ compared with $40.6 \mathrm{~cm}^{2} \cdot \mathrm{g}^{-1}( \pm 1.9 \mathrm{sE})$ for the antitranspirant-treated seedlings. However, this $12 \%$ reduction in SLW was not statistically significant. There was no significant effect of the antitranspirant treatment on yield as measured by fruit count or weight, "at either site (data not shown).

Another field experiment was set up at New Brunswick to ascertain whether reducing the Folicote concentration from 15\% to $5 \%$ in the antitranspirant formulation would reduce the apparent phytotoxicity. Although all formulations containing $0.5 \%$ X-77 with $5 \%, 10 \%$, or $15 \%$ Folicote were effective antitranspirants and increased $\Psi \mathrm{w}$ relative to control seedlings after transplanting, all three formulations had phytotoxic effects (data not shown) similar to those found in the other two field experiments. Since decreasing the Folicote concentration from 15\% to $5 \%$ did not affect its antitranspirant properties, 5\% Folicote was used in all subsequent studies.

Antitranspirant formulation phytotoxicity. The ability of various antitranspirant formulations to induce ethylene evolution in pepper leaves was evaluated as an initial index of phytotoxicity. The surfactants Biofilm and X-77 (at 0.5\%) were used because results of the in vitro dehydration screening assays (Table 1) suggested that both surfactants may enhance the antitranspirant effectiveness of Folicote. Neither surfactant, either alone or in combination with Folicote, caused any increase in the basal level of ethylene production in leaves not exposed to water stress (data not shown). However, when excised leaves were subjected to water stress by air drying until they lost $25 \%$ of their fresh weight, the surfactant X-77 alone or in combination with Folicote increased ethylene evolution above that of the control (Table 4). Folicote and Biofilm, alone and in combination, had no significant effects on ethylene production (Table 4).

In an experiment designed to simulate the low $\Psi \mathrm{w}$ experienced by pepper seedlings following transplanting into the field (e.g., Figs. 2 and 3), the surfactant X-77 $(0.5 \%)$ alone and in combination with Folicote $(5 \%)$ inhibited leaf area development and increased leaf abscission of seedlings, even after relief from stress, after they were transplanted into pots in a greenhouse (Table 5). Although Biofilm and Folicote alone and in combination elicited a slight degree of phytotoxicity (i.e., increases in leaf abscission and decreases in total leaf area as compared with control values), the effects of these treatments were not statistically significant in this (Table 5) or in a similar later experiment (data not shown). X-77 alone and in combination with Folicote tended to decrease SLW, while the other treatments had no effect. Measurements on day 19 of the experiment

Table 4. Effects of Folicote and two surfactants alone and in combination on ethylene production from excised, water-stressed (i.e., $25 \%$ loss in fresh weight) pepper leaves. All Folicote treatments were at 5\% and all surfactant (X-77 and Biofilm) treatments were at $0.5 \%$.

\begin{tabular}{llr}
\hline \hline & \multicolumn{2}{c}{ Ethylene $\left(\mathrm{nl} \cdot \mathrm{kg}^{-1}\right.$ fresh wt per hour) } \\
\cline { 2 - 3 } Treatment & Expt. 1 & Expt. 2 \\
\hline Water control & $1.094 \mathrm{a}^{\mathrm{z}}$ & $0.100 \mathrm{a}$ \\
X-77 & $3.916 \mathrm{c}$ & $2.927 \mathrm{~b}$ \\
Biofilm & $1.489 \mathrm{ab}$ & $0.147 \mathrm{a}$ \\
Folicote & $1.265 \mathrm{a}$ & $0.105 \mathrm{a}$ \\
+ X-77 & $2.592 \mathrm{cb}$ & $0.587 \mathrm{a}$ \\
+ Biofilm & $1.199 \mathrm{a}$ & $0.283 \mathrm{a}$ \\
\hline
\end{tabular}

${ }^{z}$ Mean separation in columns by Duncan's multiple range test at $P=$ 0.05
Table 5. Effects of the surfactants Biofilm and X-77 alone and in combination with Folicote on leaf area and leaf abscission of seedlings that were transplanted and subjected to water stress in the greenhouse. Water stress was relieved by irrigating pots on day 8; leaf abscission was measured on day 13.

\begin{tabular}{lcccc}
\hline \hline & \multicolumn{3}{c}{ Total leaf area $\left(\mathrm{cm}^{2}\right)$} & \\
\cline { 2 - 4 } & \multicolumn{3}{c}{ Days after transplanting } & $\begin{array}{c}\text { Leaf } \\
\text { abscission } \\
\text { Treatment }\end{array}$ \\
\cline { 2 - 4 } & 0 & 11 & 19 & $(\%)$ \\
\hline Water control & $108 \mathrm{a}^{\mathrm{z}}$ & $119 \mathrm{a}$ & $175 \mathrm{a}$ & $17.5 \mathrm{a}$ \\
X-77 & $119 \mathrm{a}$ & $56 \mathrm{c}$ & $93 \mathrm{c}$ & $58.9 \mathrm{~b}$ \\
Biofilm & $127 \mathrm{a}$ & $108 \mathrm{ab}$ & $159 \mathrm{a}$ & $33.5 \mathrm{ab}$ \\
Folicote & $97 \mathrm{a}$ & $105 \mathrm{ab}$ & $154 \mathrm{a}$ & $21.3 \mathrm{a}$ \\
$\quad+$ X-77 & $127 \mathrm{a}$ & $74 \mathrm{bc}$ & $109 \mathrm{bc}$ & $55.0 \mathrm{~b}$ \\
$\quad+$ Biofilm & $116 \mathrm{a}$ & $87 \mathrm{abc}$ & $143 \mathrm{ab}$ & $44.2 \mathrm{ab}$ \\
\hline
\end{tabular}

${ }_{2}$ Mean separation in columns by Duncan's multiple range test at $P=$ 0.05 .

(Table 5) indicated that SLW of $52.4 \pm 1.0$ in control plants was decreased to $48.2 \pm 1.1$ and $48.4 \pm 1.2$, respectively, in plants treated with X-77 and X-77 with Folicote. SLW in plants treated with Biofilm and Biofilm with Folicote was 53.6 and 53.2, respectively. We conclude from the data in Tables 4 and 5 that the surfactant X-77 at $0.5 \%$ is phytotoxic to pepper seedlings and that it was the toxic agent in the formulation used in the 1 st year of field experiments. As this surfactant increased ethylene evolution of water-stressed pepper leaves (Table 4), it is not surprising that formulations containing this compound were phytotoxic to stressed pepper seedlings (Tables 3 and 5). Tingey (1980) has pointed out that abiotic stresses, such as application of chemicals, can cause increases of 2- to 50-fold in the basal level of ethylene production in a range of crop plants. Jordan et al. (1972) has shown that ethylene can increase the extent of water stress-induced leaf abscission. It can also be concluded from the data in Tables 4 and 5 that an antitranspirant formulation containing Biofilm and Folicote tended to be less phytotoxic than one that contained X-77. Two other surfactants, Peptoil (paraffin base petroleum oil) and Ag-98 (octylphenoxpolyethyoxyethanol) were effective in enhancing the antitranspirant effectiveness of Folicote in detached leaf screening assays similar to those noted (Table 1), and in greenhouse experiments (similar to those shown in Table 2) in which we measured $r_{L}$ of leaves on well-watered seedlings (data not shown). However, in studies similar to the greenhouse experiments summarized in Table 5, which were designed to ascertain phytotoxic effects of the surfactants on seedlings exposed to transplant shock, neither surfactant performed as well as Biofilm in formulations with Folicote (data not shown).

Growth and water relations, field (1988). We also compared $\mathrm{r}_{\mathrm{L}}$ and $\Psi \mathrm{w}$ for control transplants and seedlings (kept in large pots) that were not transplanted, but subjected to the same air temperature, humidity, and radiant heat load as those transplanted. Within $1 \mathrm{~h}$ after transplanting ( 0 days $), \mathrm{r}_{\mathrm{L}}$ increased drastically in transplanted seedlings, but not in those that remained in pots (Fig. 3A). $\Psi$ w declined by $1 \mathrm{MPa}$ from initial values within 2 days after transplanting (Fig. 3B). We attribute the rapid decline in $\Psi \mathrm{w}$ and concomitant increase in $r_{L}$ that occurred in transplanted seedlings to "transplant shock".

During the 2nd year of field studies, an antitranspirant formulation containing 5\% Folicote and $0.5 \%$ Biofilm was evaluated at Bridgeton. Although $r_{L}$ in antitranspirant-treated seedlings was higher than for control plants $1 \mathrm{~h}$ and 1 day after transplanting, these differences were not significant (data not shown). 


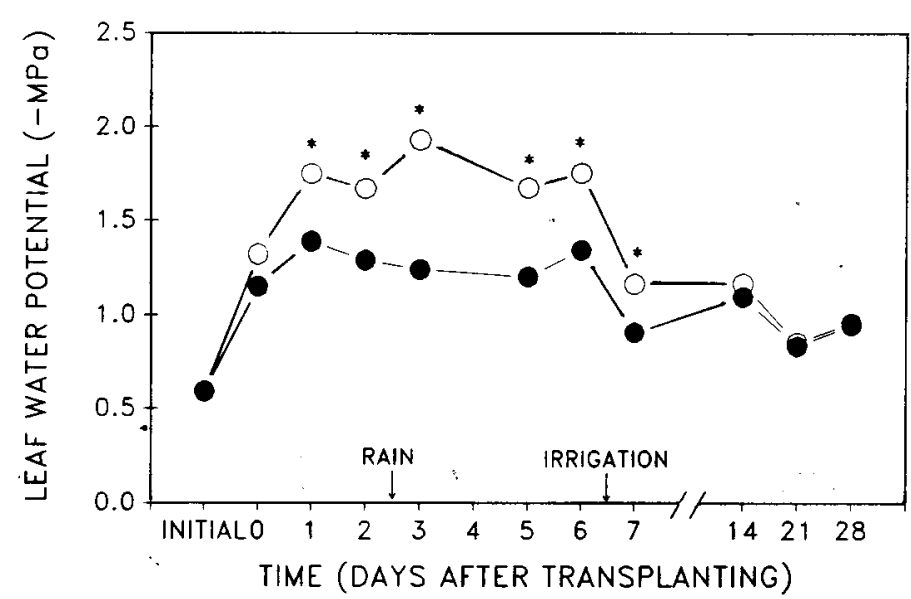

Fig. 4. Comparison of antitranspirant formulation (5\% Folicote and $0.5 \%$ Biofilm) $(-\bigcirc)$ and control $(\bigcirc-\bigcirc)$ effects on $\Psi$ w of seedlings transplanted into the field (1988). 'Denotes a significant difference $(\mathrm{P}=0.05)$ on a given day between the two treatments. Initial $\Psi_{\mathrm{W}}$ was measured in the field on seedlings just prior toremoval from the flats. Readings of $\Psi \mathrm{w}$ presented as recorded " 0 " days after transplanting were made $1 \mathrm{~h}$ after transplanting seedlings.

The antitranspirant treatment did, however, significantly increase $\Psi \mathrm{w}$ relative to the control for 7 days after transplanting (Fig. 4). Differences in $r_{L}$ were not substantial enough to be significantly different (data not shown). As noted previously, this difference in antitranspirant effects on $\mathrm{r}_{\mathrm{L}}$ and $\Psi_{\mathrm{W}}$ maybe due to the rapid rise in $r_{L}$. that occurs in transplanted seedlings (Fig. 3A). With control seedlings, initial $\Psi_{\mathrm{w}}$ depression after transplanting (i.e., compare "initial" and "day 0 " $\Psi \mathrm{w}$ values for transplanted seedlings in Fig. 3B) can result in an almost instantaneous increase in $r_{L}$ to maximum levels (Fig. 3A). Therefore, with transplanted seedlings, the rapid rise in $r_{L}$ due to $\mathrm{Y} w$ depression in control seedlings may mask the effects of the antitranspirant formulation on $r_{L}$.

In contrast to the previous year's results (Table 3), in this field study, the enhanced water status (i.e., maintenance of higher $\Psi$ w; Fig. 4) that occurred after transplanting resulted in enhanced growth of the antitranspirant-treated pepper seedlings (Table 6). The transplant shock ( $\Psi \mathrm{w}$ depression to nearly -2 $\mathrm{MPa}$ ) experienced by control seedlings (Fig. 4) had resulted in about a $40 \%$ increase in leaf abscission 2 weeks after transplanting relative to those treated (Table 6). This reduction in leaf abscission in Folicote + Biofilm-treated plants likely occurred because the formulation was an effective antitranspirant (Table 1) that at least partially reversed transplant shock (i.e., increased $\Psi \mathrm{w}$ for several days after transplanting; Fig. 4) and that was less phytotoxic to pepper seedlings than formulations containing X-77 (Tables 4 and 5). This antitranspirant-induced reduction in leaf abscission may have affected leaf area devel- opment over the course of the growing season. During the lstyear field experiment, an antitranspirant formulation with X-77 decreased total leaf area (Table 3), while in the 2nd-year field experiment, a formulation with Biofilm did not have this effect; treated seedlings maintained substantially greater leaf area than controls (Table 6). A comparison of antitranspirant formulation effects on SLW in the field experiments also suggests that replacement of X-77 with Biofilm reduced the phytotoxicity. In 1987 the antitranspirant formulation with X-77 tended to decrease SLW. The mean SLW in 1988 was $33.3( \pm 0.6) \mathrm{cm}^{2} \cdot \mathrm{g}^{-1}$ for the control and $32.7( \pm 0.1) \mathrm{cm}^{2} \cdot \mathrm{g}^{-1}$ for the $5 \%$ Folicote $+0.5 \%$ Biofilm treatment, indicating that there was virtually no reduction in SLW caused by this combination.

The enhancement of growth in antitranspirant-treated seedlings (Table 6) did not significantly (i.e., at $P £ 0.05$ ) affect fruit yield in 1988 although there were trends toward positive effects. The antitranspirant treatment had the greatest effect on early yields. At the first harvest, the control plot yielded 0.63 $\mathrm{t}$ fruit/ha; that of the antitranspirant-treated plants was $31 \%$ higher (significant at $P=0.2$ ). Total fruit weight (sum of three harvests) was 3.0 and $3.6 \mathrm{t} \cdot \mathrm{ha}^{-1}$ in control and treated plots, respectively. This represented an $18^{\prime} \%$ increase in overall yield.

We conclude that in vitro dehydration assays using detached leaves can be used as a convenient and accurate assay to screen the effectiveness of many wax emulsion/surfactant antitranspirant formulations. Experiments with Folicote and a wide range of surfactants (including ionic, nonionic, detergent, crop oil, and spreader/sticker types) at a range of concentrations indicated that formulations varied in antitranspirant effectiveness and phytotoxicity. Assay of ethylene production from detached leaves that were subjected to water stress in vitro was a sensitive and convenient screening technique to characterize relative phytotoxicity of various formulations in situ.

The field studies described in this report were designed to subject seedlings to a substantial and prolonged period of transplant shock after setting out in the field. Reductions in water stress by antitranspirants after transplanting may not be as substantial as occurred in our studies when seedlings are subjected to less severe or briefer transplant shock. However, our conditions likely simulated commercial operations where irrigation systems are often not set up until hours or even days after transplanting.

Transplant shock experienced by untreated seedlings in the four field experiments was pronounced and caused immediate (within $1 \mathrm{~h}$ ) $\Psi \mathrm{w}$ depression, resulting in increases in $\mathrm{r}_{\mathrm{L}}$ after transplanting. Differences in $r_{L}$ between control and antitranspirant-treated seedlings after transplanting were, therefore, not clear-cut. The substantial increase in $\Psi \mathrm{w}$ after transplanting in treated seedlings as compared with controls (Fig. 4) may be a better assay of antitranspirant effectiveness in the field than $r_{L}$ measurements.

Table 6. Effect of antitranspirant formulation 5\% Folicote and 0.5\% Biofilm on leaf abscission and leaf area development of seedlings transplanted into the field, 1988.

\begin{tabular}{|c|c|c|c|c|c|c|c|}
\hline \multirow{3}{*}{$\begin{array}{l}\text { Antitranspirant } \\
\text { applied }\end{array}$} & \multicolumn{7}{|c|}{ Leaf area/seedling $\left(\mathrm{cm}^{2}\right)^{2}$} \\
\hline & \multicolumn{6}{|c|}{ Days after transplanting } & \multirow{2}{*}{$\underset{\text { Leaf }}{\text { Leassion }}(\%)$} \\
\hline & 7 & 14 & 21 & 29 & 42 & 51 & \\
\hline $\begin{array}{l}\text { No } \\
\text { Yes }\end{array}$ & $\begin{array}{l}14.8 \mathrm{a}^{y} \\
39.4 \mathrm{~b}^{2}\end{array}$ & $\begin{array}{l}21.4 \mathrm{a} \\
50.4 \mathrm{~b}\end{array}$ & $\begin{array}{l}30.3 \mathrm{a} \\
78.1 \mathrm{~b}\end{array}$ & $\begin{array}{l}38.2 \mathrm{a} \\
86.7 \mathrm{~b}\end{array}$ & $\begin{array}{l}285.6 \mathrm{a} \\
545.4 \mathrm{~b}\end{array}$ & $\begin{array}{l}1195.3 \mathrm{a} \\
1788.4 \mathrm{~b}\end{array}$ & $\begin{array}{l}76.0 \mathrm{a} \\
53.1 \mathrm{~b}\end{array}$ \\
\hline
\end{tabular}

${ }^{2}$ Measured on day 14.

${ }^{y}$ Mean separation in columns by $t$ test at $P=0.05$. 
We conclude that when the wax emulsion Folicote (at $5 \%$ ) is used in an aqueous formulation with an appropriate surfactant (such as Biofilm at $0.5 \%$ ) as a foliar drench on seedlings immediately before transplanting, the formulation serves as an effective antitranspirant, substantially reversing transplant shockassociated $\Psi$ v depression. Enhancement of seedling water status (as compared with untreated transplants) for several days. after transplanting by the antitranspirant formulation results in less stress-induced leaf abscission, enhanced plant growth (i.e., leaf area) throughout the growing season, and possibly greater yield.

\section{Literature Cited}

Berkowitz, G.A. and J. Rabin. 1988. Antitranspirant associated abscisic acid effects on the water relations and yield of transplanted bell peppers,. Plant Physiol. 86:329-331.

Davies, W.J. and T.T. Kozlowski. 1974. Short- and long-term effects of antitranspirant: on water relations and photosynthesis of woody plants. J. Amer. Soc. Hort. Sci. 99:297-304.
Gale, J. and R.M. Hagan. 1966. Plant antitranspirants. Annu. Rev. Plant Physiol. 17:269-282.

Jones, H.G. 1981. Plant growth regulators and plant water relations, p. 91-100. In: B. Jeffcoat (ed.). Aspects and prospects of plant growth regulators. British Plant Growth Regulator Group, Wantage, England.

Jones, H.G. 1986. Plants and microclimate. Cambridge Univ. Press, Cambridge, England. p. 189.

Jordan, W. R., P. W. Morgan, and T.L. Davenport. 1972. Water stress enhances ethylene-mediated leaf abscission in cotton. Plant Physiol. 50:756-758.

Lipe, W.N. and J.A. Skinner. 1979. Effect of an antitranspirant on water use, growth and yield of greenhouse-grown potatoes. HortScience 14:239-241.

Lipe, W. N., K. Hodnett, M. Gerst, and C.W. Wendt. 1982. Effects of antitranspirants on water use and yield of greenhouse and fieldgrown onions. HortScience 17:242-244.

Tingey, D.T. 1980. Stress-ethylene production: a measure of plant response to stress. HortScience 15:630-633. 